\title{
The Learner Support System for Distance Education
}

\author{
Thanathnuth Chatpakkarattana, Jintawee Khlaisang \\ Faculty of Education, Chulalongkorn University, Bangkok, Thailand \\ Email: ajarnthanathnuth@gmail.com,jinmonsakul@gmail.com
}

Received 2012

\begin{abstract}
This study on 'The Development of the Interactive E-Tutorial System to Develop Problem-Solving Ability and Self-Regulation for Undergraduate Students in Open University' has the major purpose to learn about the 'Learner Support System'. In this study, the author examines and identifies the definitions of the terms 'Learner Support System' and 'Tools and Implementation to the Learner Support System for Distance Education' in order to find out what they are. The results from the study reveal that the Learner Support System for Distance Education should cover all the steps and procedures, before, during and after the learning. This enables learners or students to succeed in their learning. In addition, it is also discovered that the Learner Support System in Distance Education must be integrated. This integration means the utilization of a variety of communication tools, both online and offline, with the main aim to provide to learners the chances to learn by themselves and to enable them to succeed in their learning and to apply the knowledge they learn to their real lives in the continuous manner throughout their lives.
\end{abstract}

Keywords: Distance Education; Learner Support System; Online-Offline Learner Support

\section{Introduction}

Distance Education is a form of education management whereby learners and teachers can interact to each other from distant areas. Such interactions rely on the transfers of bodies of knowledge and experiences through various education media from teachers or lecturers to students. These educational media include traditional media such as printed media, broadcast radio and television; and new media which allow distance education system through computer and internet device, both online and offline, such as learning support computer systems, multimedia CDs and E-learning system. Distance learning also relies on both the traditional learning system or face-to-face one and innovative learning system such as e-tutorial systems. This makes learning available anywhere, anytime and for everyone. It is thus the extension of education chances for everyone, not withstanding his age or gender, to learn continuously throughout his life (Holmberg, 1998; Keegan, 1990; Srisa-arn, 1991; Nanda, 1998; Malithong, 2005; Sanksri, 2006)

Therefore, learners or students who rely on distance education system, such as students of open universities, extremely need to understand the system and learning routine and have high levels of motivation and perseverance because they have to learn by themselves through different education of media. Many other research works that concern the management of distance education system reveal that most problems discovered related to the topic are learners' feeling of isolation, the absence of personal feedback provision, technical problems concerning computers and the lacking of social interactions. These problems result in learners' cancellation their courses before finishing them (Ufi/ learndirect and Kineo, 2007). Therefore, an important aspect other than the efficient and effective management is the supportive system for learners of distance education system which can affect the entire system.

\section{Learning Support System}

\section{Meaning of Learning Support System}

Learner Support System is a system that facilitates learners and students through out their courses. As Thorpe (2003) defined, learner supports can be divided into 2 levels, namely, 1) Institutional supports and 2) Subject supports.

1) Institutional Supports is the macro system that relates to the entire education system. This macro system can be in the form of a department or a set of facilities that facilitates students who need supports when they face certain problems or obstacles in their learning.

2) Subject supports are micro systems that improve individual student's competence before, during and after the class. These micro systems enable each student to improve his performances and efficiency. This is because the courses nowadays emphasize on creating active learners whilst teachers or lecturers act as learning facilitators who encourage learners to have activities and to learn together through electronics media and new technologies. These joint activities and learning need support systems that enable learners to effectively learn each subject. Therefore, the Learner Support System is a system by which learning tools and services are provided to learners in order to facilitate them to join the learning system and to enable them to have advancement and success in their learning (Simpson, 2004; Usun, 2004; Suwannatthachote, 2009).

\section{Learning Support System of Sukhothai Thummathirat Open University}

The Learner Support System for Distance Education of Sukhothai Thummathirat Open University is comprised of institutional and subject supports, the details of which are given in the following paragraphs.

1) Institutional Support- This macro system includes many relevant work units and facilities such as the Administrations Office, the Educational Service Office, the Information Division, the Library and the knowledge Center. The Administra- 
tion Office facilitates and supports students through several actions such as to give to students the information of registrations, the office has provided to students different registration and enrollment channels such as postal services and counter services. Concerning the examination arrangement, the office holds examinations in several areas so that students can have examinations even when that are in other provinces or countries because they can have examinations in advance. This is the Walk - in - Exam system whereby students can have examinations in advance when they are ready, and know the exam results as soon as possible. Meanwhile, the Educational Service Office also supports students' learning by providing to then the learning materials, documents and face - to -face and online tuitions. Students who have questions on the document delivery and broadcast schedules can contact this office for relevant information. Another important task of this office is to provide to students educational advice in the systematic manner - before/ during/ after the learning. Such advisory services enable students to have clear understanding on the learning in distance education system. In addition, there are also student clubs to create the relationship between elder and younger students. Elder students can give learning advice to younger students throughout the courses. Another unit that supports students' learning by linking the university to students is the Information Center that students can contact through various channels that students can contact through various channels such as telephones (during work hours), cell phones, and Facebook website, which are fast and accessible. There is also the One - Stop service where by students can easily obtain answer for their question. There services make the system more convenient.

2) Subject Supports-These supports are included in the course of each subject that is opened as the e-learning course. These supports are the systems that allow learners to discuss and exchange ideas with teachers and classmates on the discussion board provided. In addition, learners can interact with each other and ask teachers some questions via personal e-mails. As for each subject, learners also have to learn by using other media such as radio broadcasting programmes, television broadcasting programmes and distance additional e-tuitions. Learners, however, still need more support systems that enable them to have advancement and success in their distance learning.

In conclusion, the distance education support system of Sukhothai Thummathirat Open University is a big system or an institutional one. To provide complete supports to learners, it is essential for the university to emphasize on the small by system which covers the preparation of methods, instrument and learning resources, both human resources and other, in order to support the learning and to facilitate all learning activities. This will enable distance education learners to succeed in their education.

\section{Development of Learner Support System for Distance Education}

The Development of the Learner Support System for Distance Education should focus on the development of both the institutional and subject supports via several tactics. The major focus is to satisfy and facilitate learners because learners or students of this program are working adults. Thus their time is limited. In addition, they do not wish to endure waiting for some delayed things (Suwannatthachote, 2009). Example of the development of the Learner Support System for Distance Edu- cation as the institutional supports are:

1) To make and improve printed media that are interesting;

2) To present clear learning directions to learners;

3) To establish the text book center as a learning source for learner; and

4) To establish local learning centers in order to enable local experts to have to teach learners in both the face - to - face and telephone manners.

\section{Subject Supports of the Learner Support System}

As for the development of the Learner Support System for Distance Education that uses computers and internet as learning channels or emphasizes on learning subject levels, or the micro system, it is suggested that computers be used as communication means to fill the gaps of time and space, in the following forms:

1) The records of learners' performances and the administrations, as well as the provision of advice before the course;

2) The provision of the information on enrollment and registration;

3) The provision of the text books in the library and E books;

4) The review of lessons and the provision of learning advice by teachers, advisors and learning supervisors;

5) The utilization of technologies such as telephones, radios, soundtracks, audiovisual media and television programs that support the communication;

6) The establishment of the support team to give services through e - mails and telephones;

7) The establishment of a database that contains frequently asked questions, as well as answers to such questions, systematically sorted and filed;

8) The online communication media for educating the learners of specific subjects, which solve practice problems;

9) The provision of tutors, both personal and subject tutors; and

10) The support and motivation for learners to study online such as the greetings and announcing tutors' work hours for learners to contact, the check of learners' learning progress and the evaluation of learners' outcomes, the monitoring of learners' achievement as set by goals, and revision of the plan and the planning for learning process.

\section{Case Study: Learner Support System of Chulalongkorn University}

The findings from research work on the Analysis and Evaluation of Learner Support System for Distance Education, Chulalongkorn University' by Praweenya Suwannatthachote (2009) reveal that the learner Support Systems for Distance Education can be divided into 2 types, namely, the Online Learner Support and the Offline Learner Support. It is also discovered that the systems can be divided into 2 levels:

1. The support systems in the institutional context which includes

1) Pre - course meeting, 2) internet registration and 3) utilization of learning management system; and

2. The support systems in the curriculum and program levels which are divided into 3 phases, namely

1) Pre - course supports which include the primary meeting and the training course of the utilization of learning management systems, 
2) During - course supports which include 1) online - offline communication channels, 2) various learning media, 3) lesson review classes, 4) integration of learning activities to the curriculum, and 5) learning facilitation by teaching assistants and course staff members; and

3) Post - course supports such as announcement of exam result announcement schedules, online registration learning coordination and special events.

In conclusion, the development of the Learner Support System for Distance Education is essential to distance students because this system supports and improves students' learning outcomes. The developer of the system needs to develop both the big and small system in order to meet all needs of students.

\section{Tools and Implement to the Learner Support System for Distance Education}

After obtaining the information on the development of the Learner Support System, it is necessary to understand the communication tools implemented to the system. Learners need to be taught to use communication tools to exchange knowledge and to share ideas. In this section, the tools and the implementation to the learner support system in the subject scale (the micro system) will be explained. Na-Songkhla (2007) categorized communication tools for supporting students' learning with the time dimension into 2 types:

\section{Synchronous Tools}

1. Synchronous tools, which allow simultaneous communication, such as

1) Online Chat or Instant Relay Chat which allows multiple students to communicate to each other at the same time. These tools are good for critiquing or asking additional questions during a real - time lecture, running group discussions and brainstorming;

2) Instant Message (IM) which emphasizes on the transfer of personal massages from senders to receivers. It is suitable for information exchange, personal conferences, running virtual work hour and running discussions;

3) Virtual Learning Environment (VLE) which enables interactions in various contexts such as 3D picture messages, virtual classroom ambience and simulate virtual situations. VLE creates virtual classroom ambience and enables teachers to give learning experiences to students.

\section{Asynchronous Tools}

1. Asynchronous tools, which allow communication at different time, such as

1) Wiki which is the use of web bases to create knowledge hubs for learners to post and change knowledge and information on web - pages. This type of communication mean is the online educational collaboration or the online encyclopedia. Learner can note and work on the information on web - pages, and monitor their woks posted on web - pages. Most wiki pages enable information search, and provides link to other woks.

2) Web-blogs are spaces for learners to note their daily learning and all links to interesting topics. In general, a web-blog belongs to a person; however, some web-blogs allow multiple writers to write their articles on them. The entries are in the time order. The newly uploaded entry is placed on top. Webblogs also allow readers to critique and tag the relevant topics. Most web-blogs have the Really Simple Syndication or Rish
Site Summary (RSS) searching system, which allows readers to follow the entries that they have interacted with. This means readers can have direct interactions with the web-blogs.

3) Forum/ Discussion Board/ Bulletin Board System - BBS, which is a communication tools that allows learners and teachers to post messages, files and information on the spaces provided. Reader can interact with and download such information. The topics of forums are sorted so that readers can read the topics that they are interested in.

These forums or boards enable teachers to follow the conversations among students. They are good tools for students to post messages and deliver files, enabling students or members to discuss the related topic and teacher to monitors students' performances.

4) E - Mails are tools that allow students and teachers to send messages, e-mails and files to receiver's' personal spaces. They support learners by enabling them to submit the assignments and ask questions to teachers, or to make appointments and collaborate with the other people. They also allow teachers to communicate to students in non-emergency cases.

5) Listserv which mainly relies on e-mails. Listserv allows people with the same interests to gather and exchange ideas, ask for helps, ask and answer questions, provide and retrieve information. Messages that a members posts will be copied and forwarded to all the members. Teachers can set a Listserv that all students can exchange information with each other and help each other.

It can be concluded that the communication tools are both synchronous and asynchronous ones which support students' learning. Teachers should recognize the importance of these communication tools. In addition, technological experts need to design these tools to appropriately support and fully improve students' learning.

These aforementioned communication tools were also mentioned in the work of Sabine Bachmayer et al (2010), in which the Learner Support System was said to be divided into 2 parts, namely, information providing part such as RSS, Streaming video/ audio, Podcast such as the VoIP system, the video conference system, IM, as well as tools that serve as well as tools that serve as information resources and communication hubs such as e-mail, web-blogs, wiki pages and social networks. These two systems enable learners to have enough information to make decisions. These two systems are interrelated to each other as shown in Figure 1.

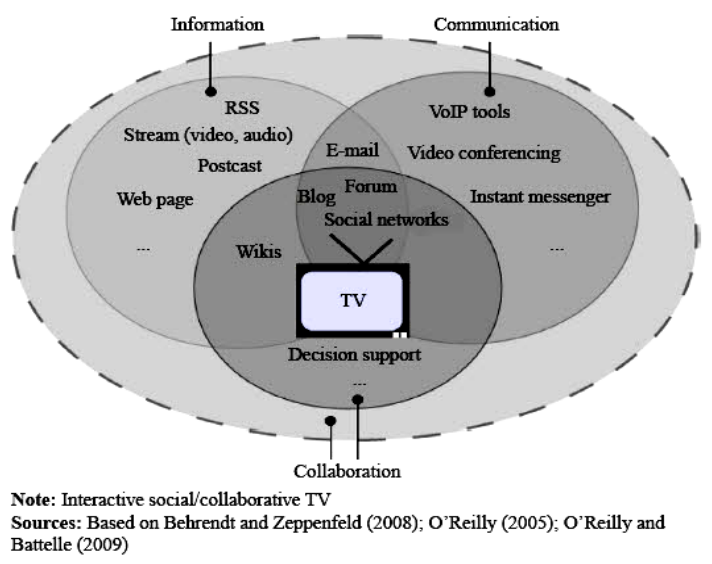

Figure 1.

Systems that Support Learners' Decision through Communication tools.

Strategic of Effective Learner Support System 
After the communication tools that support learners in the distance education are discussed, it is necessary to discuss the procedure to effectively support learners. Ufi/ learndirect and Kineo (2007) suggested 6 steps of effective learner support:

1) To identify the objectives of the learner supports included in a program. Which agree with the aims of the program;

2) To understand the natures of learners because such knowledge enables the design of the learner supports that can directly tackle to actual problems of learners such as the experiences in distance learning through electronics system, the knowledge and skills of computer and internet, the learning periods and the difficulties of subjects;

3) To draw the conceptual framework for learner supports on the based of the knowledge obtained from the steps 1 and 2 which enables the decision of the support tactics, from easy level where students can rely on themselves to advanced levels where supports interactive communication are needed, such as the search for answer from FAQS databases, the inquiries for information not found from the databases through e-mails or online chats, personal assistance through telephone, the attendance to operational conferences, class attendances, and personal advisory services.

4) To establish the networks of learner supporters which consist of experts of several fields that can support learned such as teaching experts, subject experts, teachers, program managers, IT experts and specialists in several fields, who gather together in an online community;

5) To make action plans to support the learning and to identify resource origin, which consist of 1 ) the objectives of the supports, 2) implementation channels, 3) resources hubs for each channel, 4) time and budgets needed, and 5) possible risk;

6) To test and correct which is importance because some supports are the managements of accidental events. Thus, it is not practical to design the system that can cover all problems. The test is the revision of all supports such as learning documents that might lead to certain questions from learners and need revisions and additional contents. The examples of revision are 1) To analyze learner support channels that are most used in order to improve them; 2) To analyze the most frequently asked questions which cannot be answer with the information from documents, which should be added to FAQs databases and additional learning units; and 3) If the support system via telephone is not much used, there should be active support to provision instead of such a passive system in order to meet learners' needs.

\section{The Suggestions for Designing Online Learner Support System}

Apart from the aforementioned approach, Koroghlanian and Brinkerhoff (2008) also suggested the suggestions for designing online learning that supports learners as:

1) The design of online teaching needs to include the analysis on works that are related to knowledge and skills of computer. This analysis should also include knowledge and skill of the utilization of the support system for each subject, which should be regarded as fundamental knowledge that learners need.

2) There should also be revision courses, learning materials and self-learning programs that provide to learners the knowledge on computer skills.

3) The university or academic institute that holds the courses through a learning management system which is the online learning through internet should provide immediate assistance services and related documents, which should be included in the system. This can be done by gathering most frequently asked questions in order to facilitate learners' learning.

4) It is also necessary for academic institutes to provide to learners the knowledge and skills of computer. In addition, they need to regard the knowledge and skills of computer as the fundamental knowledge that learners should have before enrolling to the learning through internet program. In case where the learning through internet program requires advanced knowledge and skills of computer, teacher should consider and set the fundamental knowledge that their students should have.

5) Concerning learners' access to the internet learning program, it is necessary for the academic institute to consider the contexts of distance learners. This is because distance learners who live outside urban areas might have problems with the access to the internet broadband services. Thus, media that require high band width might not be played. Therefore, teachers and program planners should decide what media they should use by using the information on their target audiences.

\section{Conclusion}

In conclusion, academic institutes should pay attentions to the implementation of modern technologies to support learners with clear directions. This can motivate learners to learn. In addition, this system also improves learners' efficiency and effectiveness. Thus this learner support system is an important mean that enables learners to use activities and tools to support their own learning and to satisfy themselves. Learners can control their learning by themselves, in accordance to their personal capabilities, through the Learner Support System. Meanwhile, teachers and classmates play the roles of their learning assistants. Therefore, the development of the Learner Support System should focus on both the macro and micro systems in order to cover them and link them together. This leads to the attainment of the effective management system for the distance learning in the future.

\section{Acknowledgements}

I would like to express my appreciation for the advice and guidance of Assistant Professor Dr. Jintawee Khlaisang, the chair person of the graduate committee. I also would like to show my gratitude to all the other members of the graduate committee for their guidance and suggestions. Finally, I most gratefully acknowledge my friends for all their supports throughout the course of this research.

\section{REFERENCES}

Bachmayer, S., Lugmayr, A., \& Kotsis, G. (2010). Convergence of collaborative web approaches and interactive TV program formats. International Journal of Web Information Systems, 6(1), 74 - 79. URL (last checked 26 November 2012) http://dx.doi.org/10.1108/17440081011034493

Holmberg, B. (1989). "The Concept, Basic Character and Development Potentials of Distance Education” Journal of Distance Education. 10(1), 143-156.

Keegan D. (2 ${ }^{\text {nd }}$ ed.). (1990). Foundations of Distance Education. London: Routldge.

Korohlanian, C.M. and Brinkerhoff, J. (2008). Online student's technology skills and attitudes toward online instruction. Journal of Educational Technology Systems, 36 (2), 219-244. 


\section{T. CHATPAKKARATTANA, J. KHLAISANG}

Malitghong, K. (2005). Technology and Communication for Education. Bangkok: Arun Printing.

Moore, G,M. (1993). Three types of interaction: New Perspectives. New York: Routledge.

Na - Songkhla, J. (2007). Design of Electronics Learning. Bang kok: Center of Text Books and Academic Documents, Faculty of Education, Chulalongkorn University.

Nanda, V.K. (1998). Typology of Distance Teaching System. New Delhi: Anmol Publications pvt. Ltd.

Simpson, O. (2000). Supporting Students in Open and Distance Learning. London: Kogan Page.

Sankhsri, S. (2006). Distance Education. Sukhothai Thummathirat University. Nonthaburi: Sukhothai Thummathirat University Press.

Srisa-arn, W., et al. (1991). 'Philosophy and Development of Distance Education, Distance Education Journal, Vol. 1 No. 1 Faculty of Education.
Suwannathachote, P. (2009). Analysis and Education of the Learners Support System for Distance Education earning of Chulalongkorn University. $25^{\text {th }}$ Anniversary Fund, Chulalongkorn University.

Thorpe, M. (2003). Collaborative on-line learning. In Alan Tait and Roger Mills. Rethinking Learner Support in Distance Education: Change and continuity in an international context. London: RoutledgeFalmer.

Ufi/learndirect and Kineo. (2007). Learner Support Reviewed.

URL (last checked 15 July 2012)

http://www.kineo.com/ufi/learndirect-kineo-guides/learner-support-revi ewed.html

Usun, S. (2004). Learner Support Services in Distance Education System (A case study of Turkey). Turkish Online Journal of Distance Education, 5 (4). URL (last checked 17 July 2012)

http://tojde.anadolu.edu.tr/tojde16/articles/s_usun.htm 